\title{
Intergenerational Effect of an Adverse Intrauterine Environment on Perturbation of Glucose Metabolism
}

\author{
Brigitte Reusens and Claude Remacle \\ Université Catholique de Louvain
}

\begin{abstract}
Human epidemiological and animal studies have revealed the late consequences of malnutrition during gestation and early life on the health of the offspring. These studies have highlighted the inverse relationship between birth weight and the incidence of insulin resistance and type 2 diabetes later in life. The aim of this paper is to review the different means of achieving foetal malnutrition and its consequences even for a next generation, in animal models and to identify key area for further research. We address the impact of two models of maternal malnutrition (protein restriction and caloric restriction) as well as the impact of maternal diabetes, the three maternal conditions leading to perturbed fœtal nutritional environment. Particular emphasis is given to the endocrine pancreas and the insulin sensitive tissues. More specifically, alterations of the foetal nutritional environment perturb the development of the endocrine pancreas and target the $\beta$ cell mass at birth. Some adaptations later in life may take place but stress situations such as pregnancy and ageing precipitate the animals to glucose intolerance and insulin resistance. Even the next generation features alterations in the development of the endocrine pancreas. Some mechanisms by which the foetal $\beta$ cell mass is altered are approached in this review and specific attention is paid to the amino acid profile. The preventive role of taurine is discussed.
\end{abstract}

Epidemiological observations identify phenomena without explaining the underlying mechanisms that establish their causal link. However, they provide the basis on which experimental models and hypotheses may be developed. Similarly, information derived from experimental models may highlight new targets for epidemiological research. In addition, as animal models may not always represent the human situation, conclusions derived from studies with animals need to be confirmed by epidemiologists. This highlights the need for increased interactions between different scientific disciplines in order to streamline research and validate findings.

The "thrifty phenotype" hypothesis is one hypothesis derived from epidemiological studies. It suggests that the foetus diverts nutrients to critical organs at the expense of others during times of nutritional deprivation and that this may lead to chronic degenerative diseases later in life. In other words, these diseases are programmed because of an insult in early life with lasting or lifelong consequences even for the next generations. Epidemiological data have revealed the inverse relationship between birth weight and the inci- dence of insulin resistance and glucose intolerance (Hales \& Barker, 1992). Malnutrition during pregnancy, but more specifically during the last trimester, increased the prevalence of glucose intolerance or non-insulin dependant diabetes in adulthood (Ravelli et al., 1998). Likewise, in the Indian population, insulin resistance and plasma total and LDL cholesterol concentrations at 8 years are inversely related to birth weight (Bavdekar et al., 1999). Intrauterine exposure to diabetes conveys risks for type 2 diabetes and obesity as in the Pima Indian population where diabetes has the highest prevalence (Dabelea et al., 2000). Indeed, the risk of diabetes was higher in siblings born from diabetic mother than in those born before the mother became diabetic. The effect of maternal diabetes can be thought of as a vicious cycle with consequences for the offspring extending well beyond the neonatal period.

Several animal models where foetal growth is compromised by maternal malnutrition or diabetes pointed to an intergenerational effect of the adverse intrauterine environment. This intrauterine environment is the first to which the conceptus is exposed and is strongly influenced by the mother health. Indeed, a maternal low protein diet (Kwong et al., 2000) or maternal diabetes (Pampfer et al., 1997) during the pre-implantation period in rat causes blastocyst anomalies thus compromises organ development. In this chapter, we will focus on the development of the endocrine pancreas and glucose intolerance later in life in three different models - maternal protein or caloric restriction and maternal diabetes. As these experimental models described aim to understand pathological mechanisms, this implies, as a matter of course, the search for preventive and/or therapeutic interventions. One example of such preventive treatments is addressed here, namely taurine supplementation to a protein-deficient maternal diet. The exciting findings with taurine provide a potential area of interest for further epidemiological investigations.

Address for correspondence: $\mathrm{Dr}$ Brigitte Reusens, Laboratoire de Biologie Cellulaire and WHO Collaborating Center, Université Catholique de Louvain, Louvain-la-Neuve, Belgium. Email: Reusens@bani.ucl.ac.be 


\section{Alterations of the Foetal Endocrine Pancreas}

An isocaloric low protein diet (8\% instead of $20 \%$ protein) given to dams from the first day of gestation alters the nutritional intrauterine environment. While basal blood sugar and plasma insulin was not modified, the amino acid profile was disturbed in the maternal and foetal plasma as well as in the amniotic fluid (Reusens et al., 1995). The levels of essential, branched and sulphur amino acids were reduced. The most affected amino acid in maternal and foetal plasma, amniotic fluid and in foetal islets is taurine, an amino acids that does not participate to protein synthesis (Figure 1). At birth, the offspring featured a small $(-5.5 \%)$, but significant reduction of the body weight (Snoeck et al., 1990). The reduced availability of protein and amino acids also had significant effects on the development of the endocrine pancreas. In these foetuses and new-borns, islet cell proliferation and size were reduced (Snoeck et al., 1990) and beta cell death by apoptosis was enhanced (Petrik et al., 1999) leading to a lower beta cell mass and pancreatic insulin content. These islets were also less vascularised (Snoeck et al., 1990).

Another rat model of maternal malnutrition, reduction of caloric intake by $50 \%$ from the 15 th of gestation onwards, retarded growth of the offspring more profoundly than protein restriction. In this case, beta cell proliferation was not affected, but the number of islets was lower, thereby significantly reducing the beta cell mass and pancreatic insulin content at birth (Garofano et al., 1997).

Likewise, maternal diabetes affects foetal tissue development. Prolonged high blood glucose levels had a direct impact on the development of foetal endocrine pancreas. In the rat, diabetes may be induced experimentally on the first day of gestation by streptozotocin, a chemical substance that selectively destroys beta cells. Mild or severe diabetic states ensue depending on the dose used. The total amino acid concentration was normal in mild diabetic rats, but decreased in severely diabetic rats. It was also decreased in the foetal plasma, independently of the severity of the maternal diabetes (Aerts et al., 1989). The plasma amino acid profiles of the mother and offspring were altered in both cases. Interestingly, as in the LP model, branched amino acids and taurine were most affected in the foetuses of the mild diabetic mothers. The progeny of mildly diabetic mothers was macrosomic. The development of the progeny's endocrine pancreas was enhanced. Hypertrophy and hyperplasia of foetal islets were already observed two days before birth (Aerts et al., 1990), at birth, islet cell proliferation was enhanced by $42 \%$ (Reusens-Billen et al., 1984), the volume density of the endocrine pancreas and islet vascularisation were enhanced by 30 and $36 \%$ respectively (Figure 2). The pancreatic insulin content and insulin secretion in response to glucose were also raised in these foetuses (Kervran et al., 1978). The foetuses of severely diabetic mothers were small for gestational age. Due to an overstimulation by the excessive glucose concentration, their beta cells were almost devoid of insulin granules. As a consquence, pancreatic and plasma insulin concentrations (Aerts et al., 1990) as well as insulin secretion (Kervran et al., 1978) were reduced. These findings were confirmed in foetuses of spontaneously diabetic BB rats (Verhaeghe et al., 1989).

These three experimental conditions in dams demonstrate that early nutritional events in utero impinge upon the development of a normal beta cell mass, its vascularisation and its secretory function.

\section{Evaluation of the Maternal Imprint in the First Generation}

To address the key issue of foetal and neonatal programming, two approaches were chosen. The first highlights the short-term consequences after withdrawing foetal islets from the disturbed metabolic environment by way of culture, and the second analyses the long-term consequences
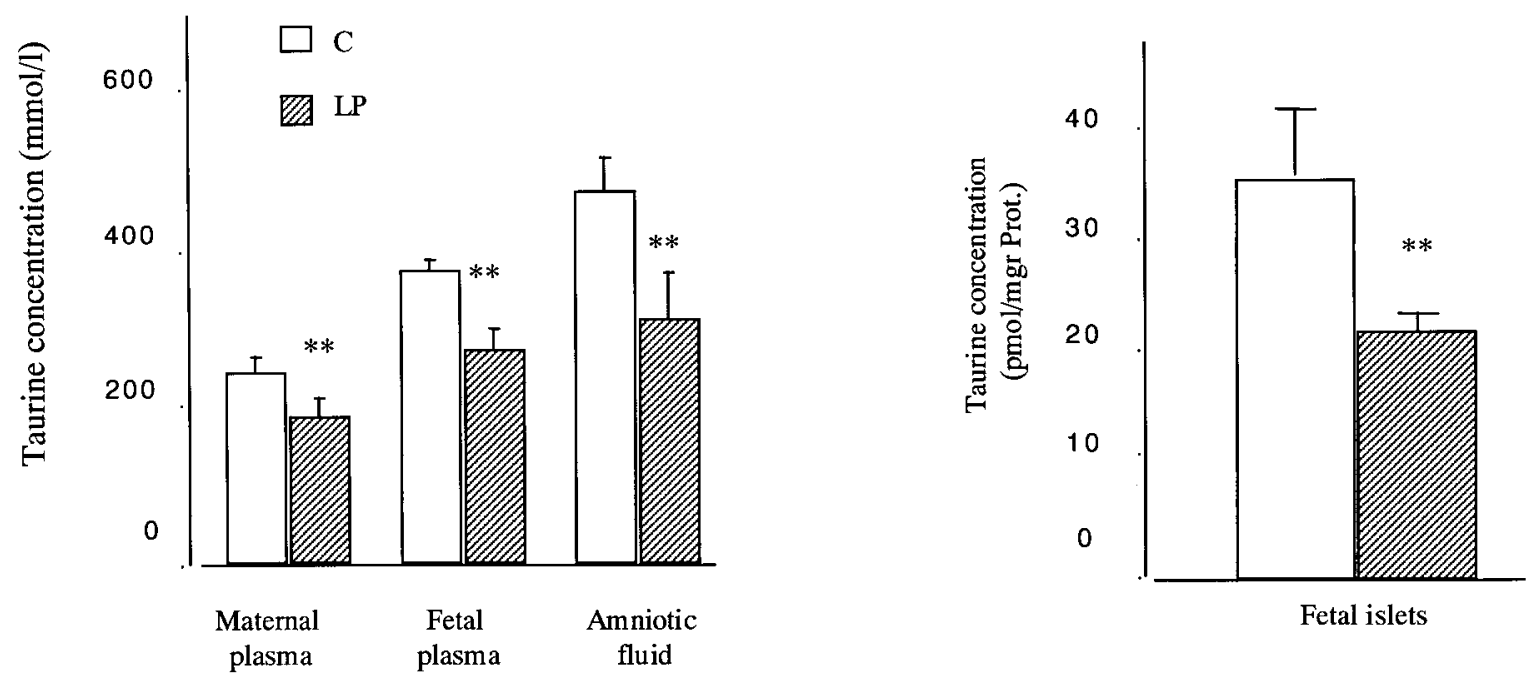

Figure 1

Taurine concentration in maternal plasma foetal plasma and amniotic fluid at 21.5 days of gestation and in foetal islets after 7 days in culture, ${ }^{* *} p<0.01$. 

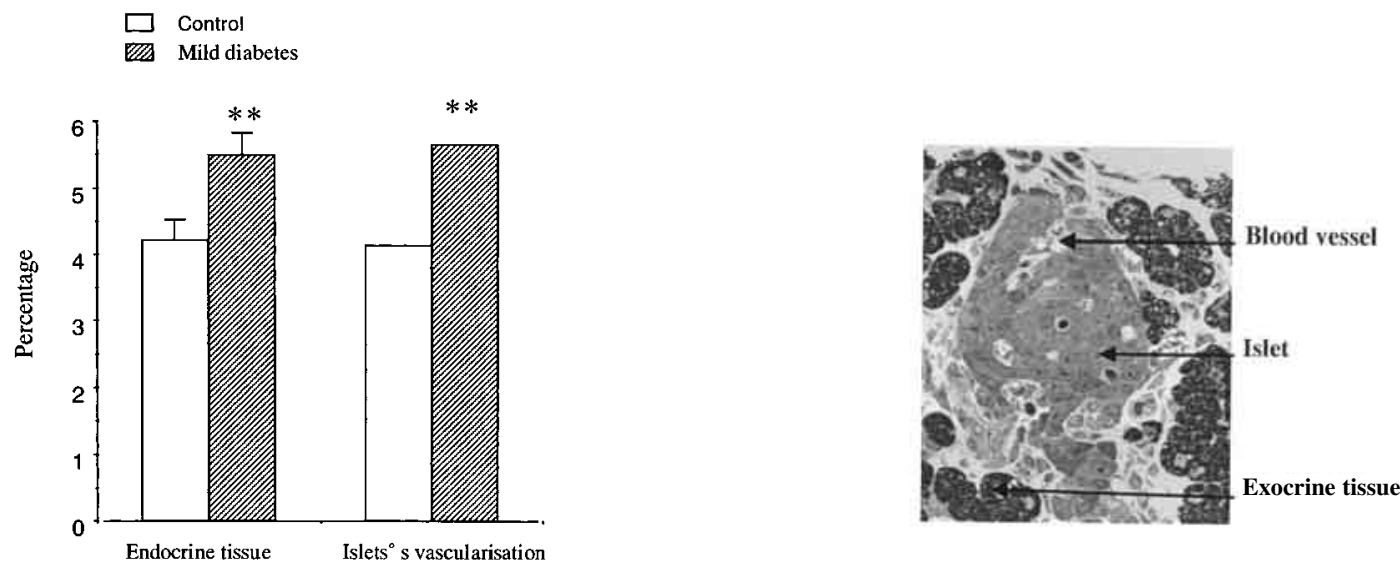

\section{Figure 2}

A: volume density of the endocrine pancreas and islets blood vessels in 21.5 old old-day fetuses of mild diabetic rat ${ }^{* *} p<0.05$.

$B$ : semi-thin section of islets of 21.5 old fetus, $I=$ islets, $B V=$ blood vessel, $E=$ exocrine tissue.

in adult offspring that have been fed a normal diet after birth or after weaning.

The study of the short term consequences showed that pancreatic cells cultured during 7 days in the same culture medium, proliferate and differentiate to form pseudo-islets mainly composed of insulin secreting cells that have retained the alteration observed in vivo. The proliferation rate of cultured LP beta cells was decreased (Cherif et al., 2001) and their insulin secretion in response to glucose and amino acids reduced by 50\% (Dahri et al., 1991). Apoptotic rate was higher (Merezak et al., in press). Moreover, these beta cells were much more sensitive to damage induced by IL-1 and nitric oxide, two molecules involved in the destruction of the beta cells in type 1 diabetes (Merezak et al., in press). The short-term consequences were also demonstrated for beta cells of foetuses from mildly diabetic rats: fotal beta cells retained their increased proliferative capacity after 7 days of culture (Reusens-Billen et al., 1984). On the other hand, beta cells from severely diabetic mothers maintained a lower proliferation rate in vitro $(7.8 \%)$ compared to in the control islets $(13.2 \%)$.

Long-term effects of the LP diet depended on the critical time windows at which the diet was applied during development. The LP diet administered only during gestation did not permanently affect the body weight of the offspring, since LP pups recovered a normal body weight immediately after birth (Dahri et al., 1991). Female, but not male offspring had a lower plasma insulin level after an oral glucose challenge at 3 months (Dahri et al., 1995). When the low protein diet was maintained during lactation and replaced by a control diet only after weaning, female as well as male offspring exhibited a lower growth rate. Plasma insulin levels were significantly reduced in female at weaning and adulthood (Figure 3). Insulin secretion in response to an oral glucose challenge was highly depressed in both sexes when compared to control animals, although both sexes had a better glucose tolerance (Reusens \& Remacle, 2001). Normal glucose tolerance in the presence of a reduced insulin release has been explained by an adaptation of the peripheral tissues through an increased number of insulin receptors in the liver, adipose tissue and hepatocytes and increased level of Glut 4 in adipocytes. This leads to an increase in whole body insulin sensitivity (Holness et al., 1999; Ozanne, Smith, et al., 1996; Ozanne, Wang, et al., 1996; Shepherd et al., 1997). The rehabilitation with $20 \%$ protein just after birth was unable, however, to fully restore the structure and function of endocrine pancreas (Dahri et al., 1995). At 3 months, islets were bigger, while the pancreatic insulin content was decreased, suggesting an increased proliferation rate, but fewer islets, as a result of reduced neogenesis during foetal development. These islets released an appropriate quantity of insulin when stimulated with glucose in vitro, but when challenged with leucine

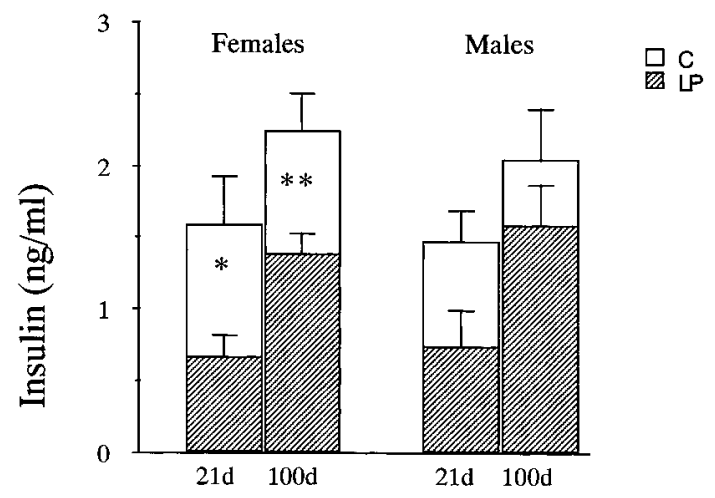

Figure 3

Plasma insulin level in female and male offspring of 21 and 100 days from mother fed on a low protein diet during gestation and lactation, ${ }^{*} p<0.05,{ }^{* *} p<0.01$. 
or arginine, their insulin secretion was significantly depressed compared to control islets (Dahri et al., 1995). Thus, altered sensitivity to amino acids of LP adult islets seems to be acquired in utero as a result of the amino acid deficient nutritional environment.

Long-term consequences were also fully apparent in offspring of mothers on caloric restriction during gestation and lactation (Garofano et al., 1998; Garofano et al., 1999). At 3 months of age, male offspring had fewer beta cells and secreted less insulin in response to an oral glucose challenge. However, as in LP offspring, no glucose intolerance was observed.

Adult offspring of severely diabetic rats kept a lower bodyweight. They had a normal endocrine pancreas and a normal plasma glucose concentration under basal conditions (Aerts et al., 1980). As in protein restriction, they maintained glucose levels within the control range, but at the expense of high insulin levels after 3 hours of glucose infusion (Van Assche \& Aerts, 1985). After euglycemic hyperinsulinemic clamp, offspring were resistant to insulin at the hepatic and peripheral levels (Holemans et al., 1991).

In summary, the endocrine pancreas is affected at birth in the different experimental models. As a consequence, insulin secretion is abnormal at young adulthood. However, in the three models, no glucose intolerance appears at that age, seemingly due to compensating adaptive mechanisms.

\section{Evaluation of the Maternal Imprint for the Next Generation}

The vulnerability of the beta cell mass acquired early in life may only be revealed in situations of increased insulin demand such as obesity, pregnancy or ageing. During pregnancy, the maternal endocrine pancreas has to adapt in response to the higher insulin demand required for foetal growth. This reversible adaptation to pregnancy consists of lowering the threshold at which glucose stimulates insulin secretion, increasing insulin synthesis and strongly raising beta cell proliferation rate (Sorenson \& Brelje, 1997). In the rat, for example, the beta cell mass nearly doubled by the end of gestation (Aerts et al., 1997; Bone \& Taylor, 1976; Parsons et al., 1992). The question, whether such an adaptation could be achieved in pregnant rats whose metabolic environment had been disturbed in early life thereby inducing an abnormal development of the endocrine pancreas was investigated. Indeed, the altered beta cell mass resulting from protein or caloric deprivation or high blood sugar levels early in life, might be a limiting factor for this adaptation. Pregnant offspring from dams fed a low-protein diet during gestation featured a very low insulin secretion after an oral glucose challenge performed at 18.5 days of gestation and became glucose intolerant (Dahri, 1995). Adaptation of the endocrine pancreas was not fully achieved, since the pancreatic insulin content in mothers fed a low protein diet during foetal life was significantly lower than in the control mothers (Reusens \& Remacle, 2001). This abnormal intrauterine milieu affected the next generation. Just before birth, the foetuses had a tendency to be hyperglycaemic. They also exhibited clearly lower plasma insulin levels, probably as a consequence of the reduced development of the endocrine pancreas. The foetal pancreatic insulin content and the volume density of the beta cell mass were indeed significantly lower (Reusens \& Remacle, 2001).

Data are also available for the adaptation to pregnancy in the calorie-restricted rat model. Although a normal adaptation was seen at 4 months in previously malnourished mothers, at 8 months they were no longer able to increase their beta cell mass (Blondeau et al., 1999). It is unclear yet, whether the mechanisms underlying the blunted increase of beta cell mass during gestation in offspring of early malnourished females are due to a lower beta cell proliferation rate, an increased rate of apoptosis, or a lack of growth hormone, placental lactogen or their receptors.

Female offspring from streptozotocin diabetic rats developed diabetes when they became pregnant. Their foetuses were macrosomic (Aerts et al., 1990), displaying islet hyperplasia, beta cell degranulation (Aerts et al., 1990), and hyperinsulinemia (Holemans et al., 1991). Studies of Grill et al., (1991) and Ktorza et al., (1990) strongly suggest that the diabetic or hyperglycaemic intrauterine environment was responsible for these alterations. Thus, the factors damaging the foetal endocrine pancreas differ in the models of maternal malnutrition.

\section{Mechanisms Responsible for the Alterations of the Endocrine Pancreas in the Progeny}

The beta cell mass is the result of three combined events, neogenesis from stem cells, proliferation of already differentiated beta cells and cell death. To detect mechanisms involved in the reduced beta mass, the proliferation cycle and beta cell death by apoptosis were investigated during the perinatal period in offspring from protein-restricted dams. In these conditions, DNA synthesis was lower at each of the foetal and postnatal day analysed. The $G_{1}$ phase was prolonged as revealed by the analysis of specific cyclins of the cell cycle. Moreover, a higher number of apoptotic cells and a lower number of cells positive for the anti-apoptotic factors IGF-1 and -2 were observed in these islets (Petrik et al., 1999). The lengthening of the cell cycle and the increased apoptotic rate in the beta cells would explain the reduced beta cell mass. Furthermore, using various secretagogues operating at different levels of the insulin secretary process, the $50 \%$ reduction in the insulin secretion in low protein pups could be attributed to alteration in the exocytosis process, the last step of insulin release (Cherif et al., 2001).

\section{Prevention of the Altered Beta Cell}

The amino acid anomalies, and more precisely the low taurine levels we observed in the protein-restricted model, were intriguing as they raised the issue of their conspicuous role in foetal growth and abnormal development of the endocrine pancreas. Taurine is a sulphur amino acid known to be indispensable during foetal and neonatal development (Sturman, 1993). Moreover, it has an antioxidant activity and is an osmolite. Therefore, its role in the development of the endocrine pancreas, was investigated. Taurine, like leucine and arginine increased insulin release of normal foetal beta cells in vitro (Cherif et al., 1996). When added to 
the culture medium, it enhanced also the sensitivity to other secretagogues (Cherif et al., 1996). By contrast, beta cells originating from foetus of dams fed a low protein diet were unable to respond to taurine in vitro, although they were capable to release some insulin in response to leucine and arginine (Cherif et al., 1998). Taurine added to the culture medium enhanced the proliferation rate of control and LP foetal beta cells (Boujendar et al., 1999). It prevented the beta cell damage caused by nitric oxide and IL-ß (Merezak et al., in press). Supplementation of the maternal low protein diet by $2.5 \%$ of taurine in the drinking water completely restored the islet cell proliferation as well as the IGF2 and VEGF content in the islets of foetuses and suckling pups. It also restored the foetal islet vascularisation by increasing the number of blood vessels (Boujendar et al., 2000). Moreover, taurine supplementation of the mother's diet normalised the insulin secretion of the foetal LP islets (Cherif et al., 1998) and prevented the beta cell damage induced by IL- $1 ß$ and nitric oxide (Merezak et al., in press). The far-reaching consequences of the lower taurine levels in LP pups are thus exemplified by these studies showing that an adequate taurine supply is indispensable for the normal development and function of foetal beta cells. Furthermore, these results demonstrate the benefit of specific dietary interventions that protect against the deleterious effects of a maternal low protein diet on the foetal endocrine pancreas.

Recent data have highlighted the role of the high glucocorticoid levels in the reduced foetal beta cell mass during maternal calorie restriction. The beta cell mass of the growth-restricted foetus was restored by a normalisation of the maternal glucocorticoid levels (Blondeau et al., 2001).

Normalisation of the maternal metabolism by transplantation of normal neonatal islets into the vena porta of severe hyperglycemic rats at day 15 of gestation lead to a strict glycemic control of the mother and the adult offspring of these transplanted rats had a normal insulin response to glucose challenge (Aerts \& Van Assche, 1992).

\section{Conclusion}

Experimental data collected in different experimental models of disturbed maternal metabolic environment point to a cascade of events throughout at least two generations. It strongly supports the intergenerational effect of an adverse metabolic environment (surfeit or failure of nutrients). As in the Pima Indian families, these finding provide strong evidence that the disturbed intrauterine environment conveys a higher risk for the development of glucose intolerance and diabetes in later life. They demonstrate also that prevention in the progeny could be achieved by treatment of the mother.

\section{Acknowledgements}

This work was supported by a grant from the partheon Trust, London, UK and a grant from the National Reserach Fund of Belgium. We are grateful to Dr J. TamaritRodriguez and Dr. J. Bustamante (Madrid, Spain) for their help in islet taurine measurements.

\section{$\overline{\text { References }}$}

Aerts, L., \& Van Assche, F. A. (1992). Islet transplantation in diabetic pregnant rats normalizes glucose homeostasis in their offspring. Journal of Developmental Physiology, 17(6), 283-287.

Aerts, L., Holemans, K., \& Van Assche, F. A. (1990). Maternal diabetes during pregnancy: Consequences for the offspring. Diabetes/Metabolism Reviews, 16, 147-197.

Aerts, L., Van Assche, F. A., Faure, A., \& Sutter-Dub, M. T. (1980). Effects of treatment with progesterone and oestradiol17 beta on the endocrine pancreas in ovariectomized rats: Ultrastructural variations in the B cell. Journal of Endocrinology, 84, 317-320.

Aerts, L., Van Bree, R., Feytons, V., Rombauts, W., \& Van Assche, F. A. (1989). Plasma amino acids in diabetic pregnant rats and in their fetal and adult offspring. Biology of the Neonate, 56, 31-39.

Aerts, L., Vercruysse, I., \& Van Assche, F. A. (1997). The endocrine pancreas in virgin and pregnant offspring of diabetic pregnant rats. Diabetes Research and Clinical Practice, 38, 9-19.

Bavdekar, A., Yajnick, C. S., Fall, C. H. D., Bapat, S., Pandt, A. N., Deshpande, V., Bhave, S., Kellingray, S. D., \& Joglekar, C. (1999). Insulin resistance syndrome in 8-year-old Indian children. Small at birth, big at 8 years or both? Diabetes, $48,2422-2429$.

Blondeau, B., Garofano, A., Czernichow, P., \& Bréant, B. (1999). Age-dependent inability of the endocrine pancreas to adapt to pregnancy; a long term consequence of perinatal malnutrition in the rat. Endocrinology, 140, 4208-4213.

Blondeau, B., Lesage, J., Dupouy, J. P., Czernichow, P., \& Bréant, B. (2001). Glucocorticoids impair fetal beta-cell development in rats; implications for glucose intolerance at adult age induced by foetal undernutrition. Pediatric Research, 281, E592-599.

Bone, A. J., \& Taylor, K. W. (1976). Metabolic adaptation to pregnancy shown by increased biosynthesis of insulin in islets of Langerhans isolated from pregnant rats. Nature, 262, 500-502.

Boujendar, S., Remacle, C., Hill, D. J., \& Reusens, B. (2000). Taurine supplementation to the low protein maternal diet restores a normal development of the endocrine pancreas in the offspring. Diabetologia, 43(Suppl. 1) 496, A128.

Boujendar, S., Reusens, B., Hoet, J. J., \& Remacle, C. (1999). Effect of amino acids on B cells and endothelial cells proliferation and in vitro interaction between the two cell types. Diabetologia, 42(Suppl. 1) 564, A152.

Cherif, H., Reusens, B., Ahn, M. T., Hoet, J. J., \& Remacle, C. (1998). Effect of taurine on the insulin secretion of islets of fetus from dams fed a low protein diet. Journal of Endocrinology, 159, 341-348.

Cherif, H., Reusens, B., Dahri, S., \& Remacle. C. (2001). A protein restriction diet during pregnancy alters in vitro insulin secretion from islets of fetal Wistar rats. Journal of Nutrition, 131, 1555-1559.

Cherif, H., Reusens, B., Dahri, S., Remacle, C., \& Hoet, J. J. (1996). Stimulatory effects of taurine on insulin secretion by fetal rat islets cultured in vitro. Journal of Endocrinology, 151, 501-506. 
Dabelea, D., Knowler, W. C., \& Pettitt, D. J. (2000). Effect of diabetes in pregnancy on offspring: Follow-up research in the Pima Indians. The Journal of Maternal-Fetal Medicine, 9, 83-88.

Dahri, S., Reusens, B., Remacle, C., \& Hoet, J. J. (1995). Nutritional influences on pancreatic development and potential links with non-insulin dependent diabetes. The Proceedings of the Nutrition Society, 54, 345-356.

Dahri, S., Snoeck, A., Reusens-Billen, B., Remacle, C., \& Hoet, J. J. (1991). Islet function in offspring of mothers on low protein diet gestation. Diabetes, 40(Suppl. 2), 115-120.

Garofano, A., Czernichow, P., \& Breant, B. (1997). In utero undernutrition impairs rat beta-cell development. Diabetologia, 40, 1231-1234.

Garofano, A., Czernichow, P., \& Bréant, B. (1999). Effect of ageing on beta-cell mass and function in rats malnourished during the perinatal periods. Diabetologia, 42, 711-718.

Garofano, A., Czernichow, P., \& Bréant, B. (1998). Beta-cell mass and proliferation following late fetal and early postnatal malnutrition in the rat. Diabetologia, 41, 1114-1120.

Grill, V., Johannson, B., Jalkanen, P., \& Eriksson, U. Y. (1991). Influence of severe diabetes mellitus early in pregnancy in the rat: Effects on insulin sensitivity and insulin secretion in the offspring. Diabetologia, 34, 373-384.

Hales, C. N., \& Barker, D. J. P. (1992). Type 2 (non-insulindependent) diabetes mellitus: The thrifty phenotype hypothesis. Diabetologia, 35, 595-601.

Holemans, K., Aerts, L., \& Van Assche, F. A. (1991). Evidence for an insulin resistance in the adult offspring of pregnant streptozotocin diabetic rats. Diabetologia, 34, 81-85.

Holness, M. J., Fryer, L. G., \& Sugden, M. C. (1999). Protein restriction during early development enhances insulin responsiveness but selectively impairs sensitivity to insulin at low concentrations in white adipose tissue during a later pregnancy. British Journal of Nutrition, 81, 481-489.

Kervran, A., Guillaume, M., \& Jost, A. (1978). The endocrine pancreas of the foetus from diabetic pregnant rat. Diabetologia, 15, 387-393.

Ktorza, A., Gaugier, D., Bihoreau, M. T., Berthault, M. F., \& Picon, L. (1990). Adult offspring from mildly hyperglycaemic rats show impairment of glucose regulation and insulin secretion which is transmissible to the next generation. In E. Shafrir (Ed.), Frontiers in diabetes research. Lessons from animal diabetes III (pp. 555-560). London: Smith Gordon.

Kwong, W. U., Wild, A. E., Roberts, P., Willis, A. C., \& Fleming, T. P. (2000). Maternal undernutrition during the pre-implantation period of rat development causes blastocyst abnormalities and programming of postnatal hypertension. Development, 127, 4195-4202.

Merezak S, Hardikar A. A., Yajnik C. S., Remacle C. and Reusens B. (2001). Intrauterine low protein diet increases fetal $B$ cell sensitivity to NO and IL.1ß: The protective role of taurine. Journal of Endocrinology, 171, (in press).

Ozanne, S. E., Smith, G. D., Tikerpae, J., \& Hales, C. N. (1996). Altered regulation of hepatic glucose output in the male offspring of protein malnourished rat dams. American Journal of Physiology, 270, E559-E564.
Ozanne, S. E., Wang, C. L., Coleman, N., \& Smith, G. D. (1996). Altered muscle insulin sensitivity in the male offspring of protein malnourished rats. American Journal of Physiology, 271, E1128-E1134.

Pampfer, S., Vanderheyden, I., \& de Hertogh, R. (1997). Increased synthesis of tumor necrosis factor-alpha in uterine explants from pregnant diabetic rats and in primary cultures of uterine cells in high glucose. Diabetes, 46, 1214-1224.

Parsons, J. A., Brelje, T. C., \& Sorenson, R. L. (1992). Adaptation of islets of Langerhans to pregnancy: Increased islet cell proliferation and insulin secretion correlates with the onset of placental lactogen secretion. Endocrinology, 130, 1459-1466.

Petrik, J., Reusens, B., Arany, E., Remacle, C., Coelho, C., Hoet, J. J., \& Hill, D. (1999). A low protein diet alters the balance of islet cell replication and apoptosis in the fetal and neonatal rat, and is associated with a reduced pancreatic expression of insulin-like growth factors-II. Endocrinology, 140, 4861-4873.

Ravelli, A. C. J., van der Meulen, J. H. P., Michels, R. P. J., Osmond, C., Barker, D. J. P., Hales, C. N., \& Bleker, O. P. (1998). Glucose tolerance in adults after prenatal exposure to famine. Lancet, 351, 173-177.

Reusens, B., \& Remacle, C. (2001). Effects of maternal nutrition and metabolism on the developing endocrine pancreas. In J. P. Barker (Ed.), Fetal origins of cardiovascular and lung disease (vol. 151; pp. 339-358). New York: Marcel Dekker.

Reusens, B., Dahri, S., Snoeck, A., Bennis-Taleb, N., Remacle, C., \& Hoet, J. J. (1995). Long-term consequences of diabetes and its complications may have a fetal origin: Experimental and epidemiological evidences. In R. M. Cowett (Ed.), Nestlé Nutrition Workshop Series, Vol 25 (pp. 187-198). New York: Raven Press.

Reusens-Billen, B., Remacle, C., Daniline, J., \& Hoet, J. J. (1984). Cell proliferation in pancreatic islets of rat fetus and neonates from normal and diabetic mothers. An in vitro and in vivo study. Hormone and Metabolic Research, 16, 565-571.

Shepherd, P. R., Crowther, N., Desai, M., Hales, C. N., \& Ozanne, S. E. (1997). Altered adipocyte properties in the offspring of protein malnourished rats. British Journal of Nutrition, 78, 121-129.

Snoeck, A., Remacle, C., Reusens, B., \& Hoet, J. J. (1990). Effect of a low protein diet during pregnancy on the fetal rat endocrine pancreas. Biology of the Neonate, 57, 107-118.

Sorenson, R. L., \& Brelje, T. C. (1997). Adaptation of islets of Langerhans to pregnancy: Beta-cell growth, enhanced insulin secretion and the role of lactogenic hormones. Hormone and Metabolic Research, 29, 301-307.

Sturman, G. A. (1993). Taurine in development. Physiological Reviews, 73, 119-147.

Van Assche, F. A., \& Aerts, L. (1985). Long term effects of diabetes and pregnancy in the rat. Diabetes, 34, 116-118.

Verhaeghe, J., Peeters, T. L., Vandeputte, M., Rombauts, W., Bouillon, R., \& Van Assche, F. A. (1989). Maternal and fetal endocrine pancreas in the spontaneously diabetic BB rat. Biology of the Neonate, 55, 298-308. 